\title{
Patterns of sponge recruitment and growth on a shipwreck corroborate chemical defense resource trade-off
}

\author{
Joseph R. Pawlik ${ }^{1, *}$, Timothy P. Henkel ${ }^{1}$, Steven E. McMurray ${ }^{1}$, \\ Susanna López-Legentil ${ }^{1}$, Tse-Lynn Loh ${ }^{1}$, Sven Rohde ${ }^{2}$ \\ ${ }^{1}$ Department of Biology and Marine Biology, Center for Marine Science, 5600 Marvin K Moss Lane, \\ University of North Carolina Wilmington, North Carolina 28409, USA \\ ${ }^{2}$ Leibniz-Institut für Meereswissenschaften, Universtät Kiel, Duesternbrooker Weg 20, 24105 Kiel, Germany
}

\begin{abstract}
Fundamental theories of resource allocation for terrestrial plants predict that species investing in chemical defenses should be slow growing or less fecund, while undefended species should mitigate consumer effects by diverting energy to growth and reproduction, thereby also enhancing their ability to colonize open space. As for some plant communities, sponges on Caribbean coral reefs include chemically defended species and undefended species that tolerate consumer damage. We surveyed the sponge community on the $155 \mathrm{~m}$ long wreck of the USS 'Spiegel Grove' $\left(\sim 1583 \mathrm{~m}^{2}\right.$ deck surface), which was intentionally sunk $4 \mathrm{yr}$ previously in 2002 as an artificial reef off Key Largo, Florida, USA, to determine the relative abundance of undefended and defended species on previously uncolonized habitat compared to an adjacent reef at a similar depth and with similar topography. As predicted by theory, chemically undefended sponge species were significantly more abundant $(96.0 \%)$ and larger on the shipwreck than on adjacent coral reef $(15.2 \%$; G-test, p < 0.0001). On a subsequent survey 18 mo later, the first recruits of 6 chemically defended sponge species were discovered, suggesting that the sponge community on the wreck is in transition toward that occurring on adjacent reefs. Although more definitive replicated experiments remain to be performed, these results corroborate the resource trade-off hypothesis as applied to the evolution of chemical defenses among sponge species on Caribbean reefs.
\end{abstract}

KEY WORDS: Predation · Optimal defense $\cdot$ Tolerance $\cdot$ Coral reef Resale or republication not permitted without written consent of the publisher

\section{INTRODUCTION}

Central to theories of terrestrial plant defenses against consumers is the Optimal Defense Hypothesis, which proposes that defenses are costly, and come at the expense of other functions such as growth and reproduction (Rhoades 1979). Further, linked to tradeoffs in resources is the idea that less defended plants may adapt to tolerate consumer damage (Stowe et al. 2000). Although increasingly complex (see review in Stamp 2003), plant defense theory remains the framework of choice for investigations of defense in other systems (e.g. Berenbaum 1995, Cronin \& Hay 1996, Cronin 2001, Pavia et al. 2002).
The theoretical framework of terrestrial plant defenses is of particular relevance to the sponge community of Caribbean coral reefs. Sponges are benthic, sessile, liberate dispersive propagules, and elaborate a diverse array of secondary metabolites (Pawlik 1997). They dominate Caribbean coral reefs, considering the overall biomass of sponges, from shallow to deep water and including the communities within the reef framework (e.g. Schmahl 1991). In many respects, Caribbean coral reef sponge ecology is much simpler than that of many terrestrial plant communities, and therefore a better subject for investigations testing theory: community composition is remarkably consistent across the entire biogeographic region, space is the 
primary limiting resource (there are few interactions as complex as those among plants, e.g. for space, light, nutrients, soil chemicals, etc.), only few large predators (angel- and parrotfishes, turtles) drive consumption, with little or no effect from insect equivalents (Pawlik 1997), and all of the component competitors, predators and prey are extant (no extinct mega-consumers, e.g. Levin et al. 2002).

Before the chemical ecology of the system was better understood, it was believed that consumers had little effect on Caribbean sponge communities, because sponge-eating fishes were thought to spread their predatory activities over a wide variety of sponge species to the detriment of none in particular (Randall \& Hartman 1968, Wulff 1994). However, subsequent laboratory and field experiments revealed 3 distinct categories of sponges within the community (Pawlik et al. 1995, Pawlik 1997, 1998): (1) defended species that are unpalatable to consumers because they contain secondary metabolites (poor tolerance, well-developed defense; see definitions in Stowe et al. 2000); (2) palatable species that are grazed by consumers and yet as common as defended species on the reef (well-developed tolerance, poor defense); and (3) preferred species that are rapidly consumed when transplanted to the reef, and are found only in refuge habitats (e.g. within the reef framework; poor tolerance and defense). The secondary metabolites responsible for chemical defenses of many sponge species have since been isolated and identified using bioassay-guided fractionation and field experiments with natural populations of reef consumers (e.g. stevensine from Axinella corrugata, Wilson et al. 1999; formoside B from Erylus formusus, Kubanek et al. 2000). The activity of the oroidin class of defensive metabolites (from the common genus Agelas) has been fully characterized at the molecular level using synthetic compounds (Lindel et al. 2000). Some defended sponge species contain metabolites that play multiple roles, such as allelochemical or antifouling defenses, in addition to predator deterrence (Kubanek et al. 2002). However, perhaps more interesting are the palatable species, which appear to compensate for the lack of chemical defenses through higher larval output (Lindquist et al. 1997) and enhanced rates of healing and growth (Walters \& Pawlik 2005).

Application of plant defense theory predicts that palatable sponge species would more rapidly colonize free space on Caribbean reefs than defended species because their abundant propagules are more likely to encounter free space, because they grow more rapidly after recruitment, or because of some combination of these 2 factors. Unfortunately, it is difficult to test this prediction with replicated manipulative experiments; destructive clearing of coral reefs would be highly impractical, and natural clearing by intense storm events does not remove sponge fragments from reef interstices from which survivors rapidly grow.

On 11 June 2002, the $155 \mathrm{~m}$ long, decommissioned US Navy Landing Ship Dock 'Spiegel Grove' was intentionally sunk as an artificial reef in $40 \mathrm{~m}$ of water on sand substratum off Key Largo, Florida, USA. After discovering that sponges had recruited to the decks of the wreck, we surveyed them in November 2006. We then surveyed Dixie Shoals reef, the nearest hardbottom substratum located $800 \mathrm{~m} \mathrm{NW}$ (inshore) of the wreck. Our prediction, based on the information above, was that the sponge community on the wreck would be dominated by palatable species, while the adjacent reef would have a mixed population of palatable and unpalatable sponge species characteristic of most Caribbean coral reefs (Pawlik et al. 1995).

\section{MATERIALS AND METHODS}

Sponge cover was largely restricted to the horizontal decks of the USS 'Spiegel Grove' $\left(25^{\circ} 04^{\prime} \mathrm{N}\right.$, $80^{\circ} 18.65^{\prime} \mathrm{W}$; Fig. 1). Line intercept transect surveys were conducted to estimate sponge cover on the fore, mid and aft decks $(27,19$ and $28 \mathrm{~m}$ depth, with surface areas of approximately 258,455 , and $870 \mathrm{~m}^{2}$, respectively) in November 2006 and on the adjacent reef, Dixie Shoals (800 m away, $25^{\circ} 4.28^{\prime} \mathrm{N}, 80^{\circ} 19.05^{\prime} \mathrm{W}, 15 \mathrm{~m}$ depth), in May 2007. Either 6 or 7 transects, each $10 \mathrm{~m}$ in length, were surveyed using standard methods (English et al. 1997). Field work on the USS 'Spiegel Grove' was performed by 6 divers using nitrox mixed gas or decompression SCUBA diving. The shipwreck was revisited 18 mo after the initial survey (May 2008) to qualitatively assess the sponge community and to check for the recruitment of new sponge species.

To estimate maximum rates of sponge growth, the 5 largest individuals that could be found of the 8 most common species on the wreck were collected and their volume determined by seawater displacement. Sponges were scraped carefully from the deck and brought to the surface, where they were transferred to tubs containing seawater and, if necessary, cut to smaller sizes underwater with a scalpel. Sponge pieces were then removed from seawater and drained for $3 \mathrm{~s}$ before being placed in a full bucket of seawater with a spigot at the top, from which the overflow volume was carefully measured. The volume of sponge tissues was compared across all species using analysis of variance (ANOVA) on log transformed data to meet the assumptions of ANOVA.

Classification of sponge species as defended or palatable was based on published data from feeding assays employing the bluehead wrasse Thalassoma bifasciatum (Pawlik et al. 1995 Walters \& Pawlik 2005). 

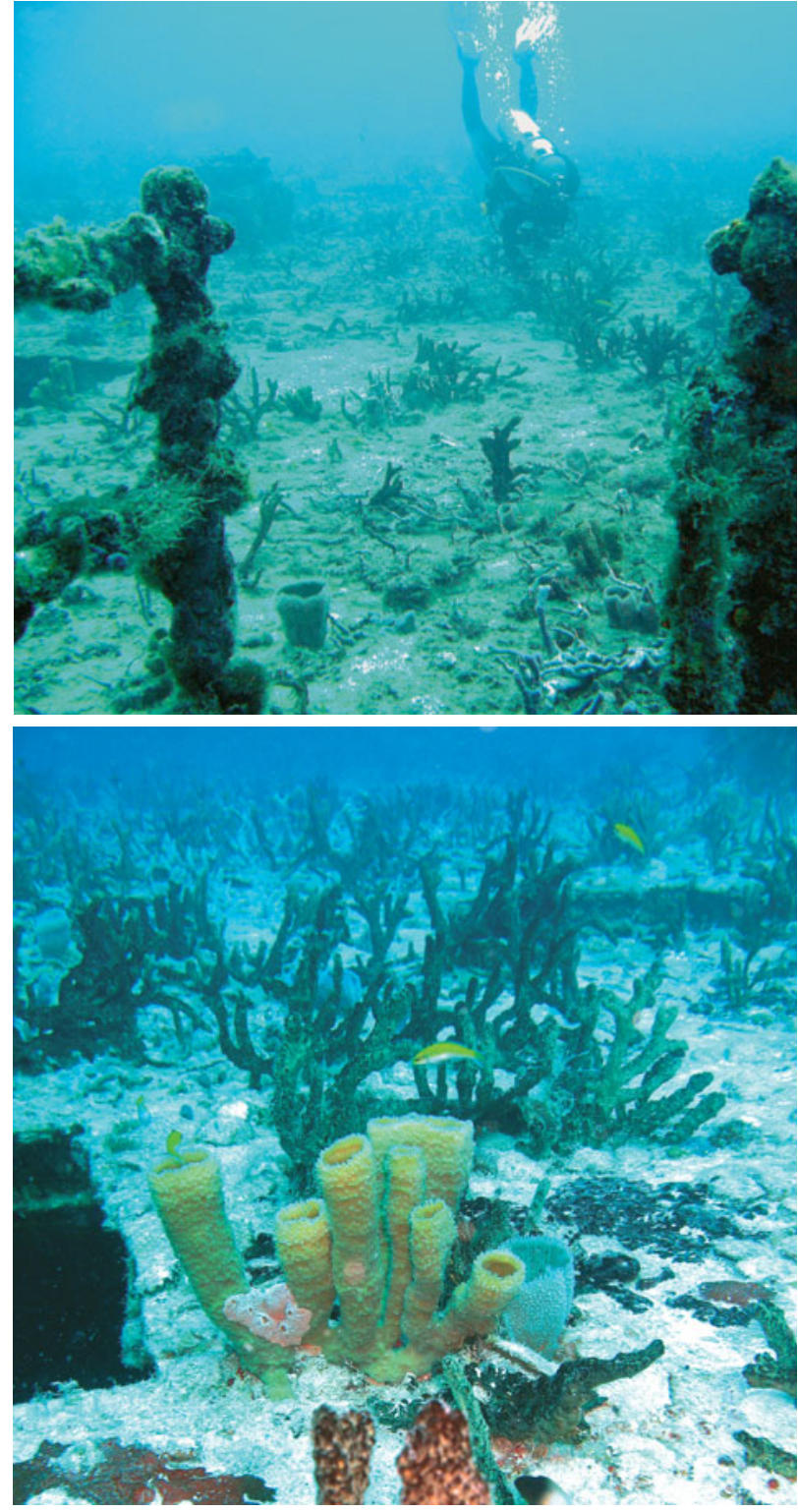

Fig. 1. Horizontal deck of the shipwreck USS 'Spiegel Grove' 4 yr after sinking

One sponge species found on the wreck, Strongylacidon sp., did not appear in these previous studies, and its feeding deterrent properties were determined following Pawlik et al. (1995). A G-test was performed to determine whether the proportion of palatable sponges on the wreck was significantly different to those on the adjacent Dixie Shoals reef.

\section{RESULTS}

On average, sponges covered $5.7,12.0$ and $6.8 \%$ of the fore, mid, and aft decks, respectively, of the USS

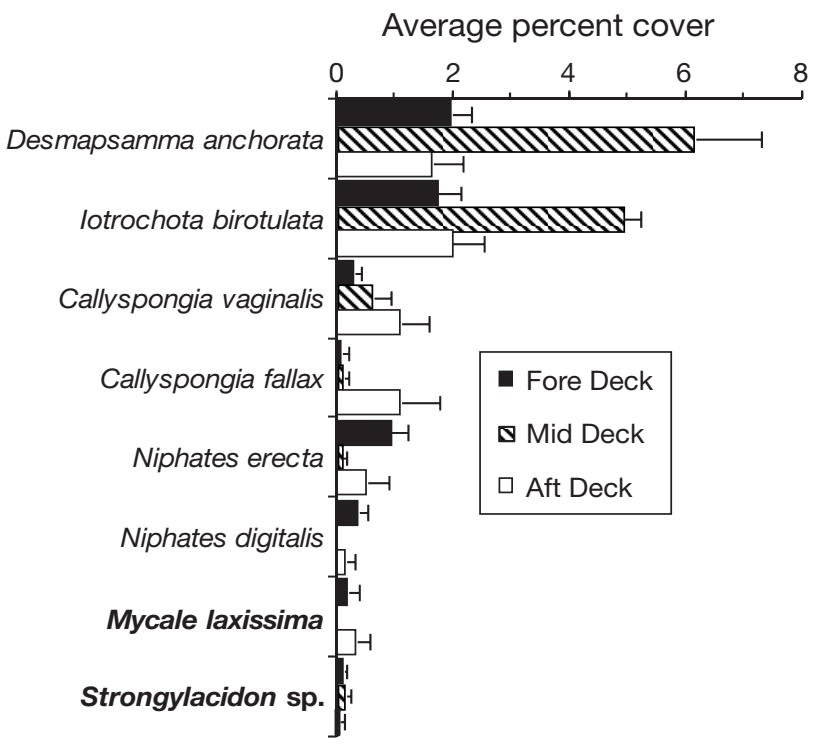

Fig. 2. Line intercept transect estimates of percentage cover of sponges on the 3 horizontal deck areas of the shipwreck USS 'Spiegel Grove', November 2006. Means + SE. Chemically defended species in bold

'Spiegel Grove' (Fig. 2). The 6 most abundant of the 8 species surveyed were in the palatable category (Pawlik et al. 1995, Walters \& Pawlik 2005), (Fig. 2). Strongylacidon sp., which was least abundant, had not previously been assayed, and yielded an unpalatable extract (mean of 1.67 of 10 pellets eaten, $\mathrm{SD}=2.08, \mathrm{n}=$ $3)$. Mean sponge coverage on the adjacent Dixie Shoals reef was $2.5 \%( \pm 1.0$; Fig. 3$)$, with the 3 most abundant species in the defended category, and only 4 of 10 species in the palatable category. The proportion

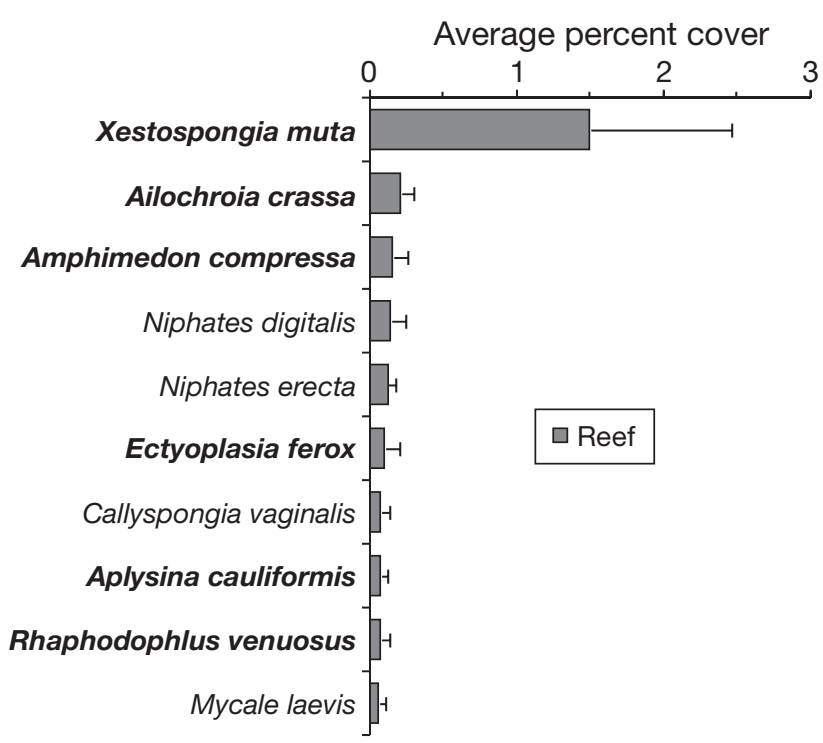

Fig. 3. Line intercept transect estimates of percentage cover of sponges on Dixie Shoals reef, November 2006. Means + SE. Chemically defended species in bold 
of palatable sponges on the wreck $(96.0 \%)$ was significantly greater than that on the adjacent Dixie Shoals reef $(15.2 \%$; G-test, $\mathrm{p}<0.0001)$.

The largest sponges on the wreck were the vasiform species Callyspongia vaginalis and C. fallax (Fig. 4), which were significantly larger than the 6 other species present (ANOVA, df $=39, F=27.1, \mathrm{p}<0.0001$, Tukey Kramer HSD multiple comparison) and extended well above the surface of the deck. Of the remaining 6 species, Desmapsamma anchorata, Iotrochota birotulata and Niphates erecta were rope-form, Niphates digitalis and Mycale laxissima were vasiform and Strongylacidon sp. formed small mounds. Spongeeating fishes, particularly several pairs of gray angelfish Pomacanthus arcuatus, were observed feeding on sponges on the wreck.

In a subsequent qualitative assessment of the shipwreck 18 mo after the initial survey, the sponge species found in earlier observations dominated the community assemblage. However, at least 6 new sponge species had recruited to the wreck at very low densities ( 1 to 20 individuals). Individuals of most of these new species, not observed in previous surveys despite careful examination of the wreck surface, were all small $(<10 \mathrm{~cm})$. In order of abundance, they were: Scopalina (= Ulosa) ruetzleri, Phorbas amaranthus, Rhaphidophlus venuosus, Ircinia sp. (strobilina or felix), Verongula sp. (gigantea or ridida), and Aplysina cauliformis. Pawlik et al. (1995) determined that all of these species were chemically defended.

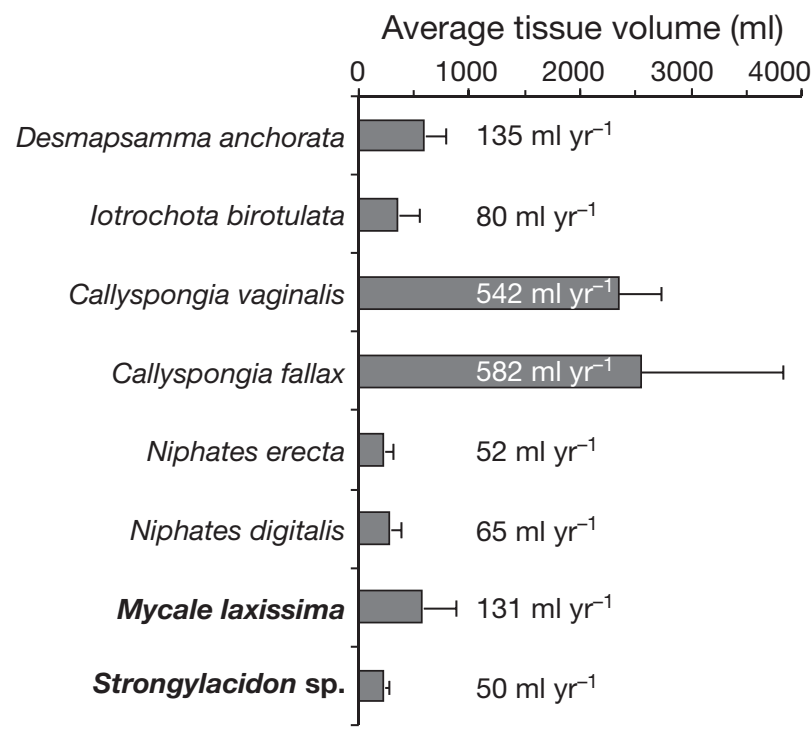

Fig. 4. Tissue volume of sponges collected from the decks of the shipwreck USS 'Spiegel Grove' as in Fig. 2. $\mathrm{n}=5$ largest individuals of each species that could be found. Means + SD. Rate of growth assumes growth period from June 2002 to November 2006 (see 'Discussion' for limitations of these estimates). Chemically defended species in bold

\section{DISCUSSION}

Besides reef-building corals, the dominant benthic organisms of Caribbean coral reef ecosystems are algae, sponges and gorgonian corals, all of which have elaborate chemical defenses (Hay \& Fenical 1996). The sponge community appears to have followed a different evolutionary trajectory from gorgonians, which are all potently chemically defended (O'Neal \& Pawlik 2002). While most algae on Caribbean reefs are also chemically defended from a more diverse set of macro- and microconsumers (Bolser \& Hay 1996), variations in defenses across species allow some to dominate under lower levels of herbivory (Morrison 1988), which may imply a resource trade-off between chemical defenses and growth. However, the sponge fauna is different from gorgonians and algae in that it includes an assortment of large, chemically defended and undefended species (Pawlik et al. 1995, Pawlik 1997, 1998). Palatable species such as Callyspongia vaginalis and Niphates digitalis frequently show evidence of grazing in the field, and regenerate tissue lost to grazing in a matter of days (Walters \& Pawlik 2005), much like terrestrial plants that have adapted to tolerate consumer damage (Stowe et al. 2000). Moreover, many of these same palatable species brood and produce larvae most of the year (Lindquist et al. 1997, T. P. Henkel pers. obs.), while chemically defended species reproduce only infrequently (e.g. Tsurumi \& Reiswig 1997). The rapid colonization of palatable sponge species on the free space provided by the wreck of the USS 'Spiegel Grove' is consistent with the predictions of the hypothesis that there is a resource trade-off between chemical defenses and reproduction or growth among Caribbean reef sponges. We are conducting on-going small-scale, replicated experiments that independently test patterns of growth and reproduction in chemically defended and undefended sponge species, the results of which also support the resource trade-off hypothesis (J. R. Pawlik unpubl. data); however, few experimental manipulations can match the scale of the study described herein, and seldom are results so clear.

The community of sponges on Dixie Shoals reef was chosen for comparison with that on the wreck because it is the closest $(800 \mathrm{~m})$ across the sandy bottom, making it the nearest (but not necessarily the only) source of propagules for recruitment to the wreck. Additionally, Dixie Shoals reef is at nearly the same depth as the mid deck of the wreck (15 vs. $19 \mathrm{~m}$, respectively), and it has a flat, level topography that is similar to the surface of the wreck. Sponges on the wreck are likely the products of larval recruitment only, rather than the products of sponge fragments transported from the reef by storms, because the horizontal deck surfaces were a minimum of $15 \mathrm{~m}$ above the sandy bottom onto 
which any sponge fragments would be swept by tides or currents. There was no evidence that the substratum difference between the wreck (epoxy-painted steel) and the flat reef (limestone) influenced sponge community compositions. The wreck surface had become fouled mostly by encrusting bivalves (e.g. Chama and Spondylus spp.) and tube-forming worms that develop a limestone substratum similar to adjacent reefs. Moreover, we have seen no differential colonization on anthropogenic structures and debris (including rusting and painted steel) by defended versus palatable sponges at our other study sites on shallow reefs in Florida and the Bahamas (J. R. Pawlik pers. obs.).

While percentage coverage of sponges on Dixie Shoals reef was less than half that on the wreck, the species surveyed on this natural reef were typical for the Caribbean, with 7 of 10 species also listed on a composite abundance ranking of the 10 most common sponges on shallow-water Caribbean reefs (compiled from surveys on reefs off Cuba, Venezuela, the US Virgin Islands and the Florida Keys, Pawlik et al. 1995; Table 1). We observed greater sponge coverage on reefs with more topographic complexity but further from the wreck (e.g. sponge cover was more than twice as high on North Dry Rocks reef), but the species composition matched that in Table 1 for Caribbean reefs in general. The fact that sponge coverage on the mid deck of the wreck was almost 5-fold greater than on adjacent Dixie Shoals reef suggests that the trade-off strategy of palatable sponges enhances their ability to recruit to free space beyond that of other competitive rivals. We found no recumbent or upright gorgonian corals on the wreck, and only a few, small hard coral recruits on the deck surface during the initial survey, with many more coral recruits (and greater species diversity) 18 mo later.

The difference in the overall pattern of undefended versus defended sponges colonizing the wreck com- pared to the adjacent reef was strikingly clear, but some of the species involved deserve further comment. The species with the highest cover on the wreck, Desmapsamma anchorata (= Holopsamma helwigi), is not among the most common species on the reef (Table 1), although we found it in moderate to low abundance at a nearby study site (North Dry Rocks reef), showing evidence of predation. This species may be transitional between the preferred and palatable categories (see 'Introduction'), and may gain some protection from sponge-eating fishes on the wreck. While angelfishes were abundant on the wreck, we did not observe parrotfishes, filefishes, or trunkfishes, and these different sponge predators may have different preferences (Dunlap \& Pawlik 1996, 1998). The same is true for Callyspongia fallax, which is also found in low abundance on adjacent reefs. Another species that may not clearly fit into a palatability category may be Mycale laxissima, which is well defended chemically (Pawlik et al. 1995), yet often has developing larvae in its tissues (J. R. Pawlik pers. obs.)

Sponge coverage on the wreck as determined with the 2-dimensional line intercept method (Fig. 2) does not provide an estimate of sponge biomass, because many sponge species with branching or vasiform morphologies grow upward into the water column. The largest individual sponges on the wreck were the vasiform Callyspongia vaginalis and C. fallax (Fig. 4), with mean volumes of $\sim 2.5 \mathrm{l}$. Assuming a linear rate of growth from the original date of the sinking of the USS 'Spiegel Grove' (11 June 2002), the very earliest point in time when larval recruitment could have occurred, these species grew $\sim 550 \mathrm{ml} \mathrm{yr}^{-1}$ (Fig. 4). To our knowledge, these are among the first reported rates of sponge growth that begin with larval recruits (cf. Wilkinson \& Cheshire 1988), unlike growth estimates that rely on changes to the volume of full-sized sponges over time (e.g. McMurray et al. 2008). How-

Table 1. Most abundant sponges on Caribbean reefs in general, on Dixie Shoals reef, and on the USS 'Spiegel Grove' shipwreck (November 2006). Chemically defended species are in bold, undefended species are not in bold (see 'Materials and methods'). The composite list for Caribbean reefs is based on an analysis in Pawlik et al. (1995) for surveys from Cuba, Venezuela, the US Virgin Islands and the Florida Keys

\begin{tabular}{|llll|}
\hline & Caribbean reef composite & Dixie Shoals reef & USS 'Spiegel Grove' shipwreck \\
\hline 1 & Scopalina ruetzleri & Xestospongia muta & Desmapsamma anchorata \\
2 & Ectyoplasia ferox & Ailochroia crassa & Iotrochota birotulata \\
3 & Niphates digitalis & Amphimedon compressa & Callyspongia vaginalis \\
4 & Callyspongia vaginalis & Niphates digitalis & Callyspongia fallax \\
5 & Mycale laevis & Niphates erecta & Niphates erecta \\
6 & Niphates erecta & Ectyoplasia ferox & Niphates digitalis \\
7 & Smenospongia aurea & Callyspongia vaginalis & Mycale laxissima \\
8 & Iotrochota birotulata & Aplysina cauliformis & Strongylacidon sp. \\
9 & Aplysina cauliformis & Mycale laevis & \\
10 & Amphimedon compressa & & \\
\hline
\end{tabular}


ever, the growth rates reported here are almost certainly underestimates, because growth is likely not linear from recruitment onward, and the recruitment of sponge larvae probably did not occur for many months after the wreck was sunk; in fact, sport divers reported very little fouling on the wreck surface more than $1 \mathrm{yr}$ after sinking (August 2003). Recognizing that these growth rates are conservative, they are nevertheless the first estimates of growth from recruitment to fullsize for these species, and the total growth of Callyspongia spp. over 4 yr reported here is nearly 5 -fold greater than that reported by Wilkinson \& Cheshire (1988) for Verongula and Ircinia spp. over $5 \mathrm{yr}$ on a Jamaican reef (assuming $1 \mathrm{ml}$ volume $=1 \mathrm{~g}$ wet mass).

By any measure, palatable sponge species dominated the wreck 4 yr after sinking, in spite of the large sponge-eating angelfishes that we observed grazing on them. These results corroborate the resource allocation trade-off hypothesis that 2 classes of sponges occur on Caribbean reefs: chemically undefended species that grow rapidly, tolerate grazing, and reproduce prolifically, and chemically defended species that grow more slowly and reproduce less frequently. While this study is based on a single wreck (although the 3 separate decks were at different depths), it is difficult to imagine a practical replicated experiment providing a similar spatial scale $\left(\sim 1583 \mathrm{~m}^{2}\right)$ subject to larval recruitment without the confounding effect of invasion by asexual fragments (see Oksanen 2001 for a discussion of pseudoreplication, deductive experiments, importance of scale, and trade-offs in experimental design).

Recognizing the limitations of this non-replicated study, we nevertheless find no parsimonious explanation beyond the compelling one presented above for the distinct pattern of sponge recruitment on the wreck. With a null hypothesis that sponge species on Caribbean reefs have equal potential for recruitment and growth, the expected pattern should be approximately equal recruitment of chemically defended and undefended species, because they each make up about half of the top 10 species in a composite ranking of sponges on Caribbean reefs and on the most proximate reef to the wreck (Table 1). However, 4 of the 8 sponge species on the wreck are palatable species common to Caribbean reefs, and none of the common chemically defended reef species recruited to the wreck (Table 1).

Further supporting the resource allocation trade-off explanation, the follow-up qualitative assessment of changes to the sponge community on the wreck 18 mo after the initial survey found that at least 6 new species had recruited, all of which were small, in very low abundance, and chemically defended. Of these species, two were among the 10 most abundant on Dixie
Shoals reef (Aplysina cauliformis, Rhaphidophlus venuosus) and a third was among the most common species on Caribbean reefs in general (Scopalina ruetzleri) (Table 1). Apparently, the sponge community structure on the wreck is now in transition from one dominated by rapidly recruiting, fast-growing, chemically undefended species that are subject to predation to one containing slower-recruiting and -growing, chemically defended species. We encourage further tests of the trade-off hypothesis using a replicated experimental design or by monitoring similar artificial structures after deployment on or near Caribbean reefs, and we intend to continue monitoring the decks of the USS 'Spiegel Grove' with the prediction that the sponge community will change over time to approximate that found on adjacent reefs.

Acknowledgements. Funding was provided by the National Science Foundation, Biological Oceanography Program (OCE-0095724, 0550468) and by NOAA's Undersea Research Center at the University of North Carolina at Wilmington (NA 96RU-0260). Sponge collections in Key Largo, Florida, were conducted under National Marine Sanctuary Permit FKNMS2001-021 in compliance with the laws of the State of Florida and the USA. We thank the NURC technical diver support staff for training and assistance with field work.

\section{LITERATURE CITED}

Berenbaum MR (1995) The chemistry of defense: theory and practice. Proc Natl Acad Sci USA 92:2-8

- Bolser RC, Hay ME (1996) Are tropical plants better defended? Palatability and defenses of temperate versus tropical seaweeds. Ecology 77:2269-2286

Cronin G (2001) Resource allocation in seaweeds and marine invertebrates: chemical defense patterns in relation to defense theories. In: McClintock JB, Baker BJ (eds) Marine chemical ecology. CRC Press, Boca Raton, FL, p 325-354

Cronin G, Hay ME (1996) Within-plant variation in seaweed palatability and chemical defenses: optimal defense theory versus the growth-differentiation balance hypothesis. Oecologia 105:361-368

Dunlap M, Pawlik JR (1996) Video-monitored predation by Caribbean reef fish on an array of reef and mangrove sponges. Mar Biol 126:117-123

Dunlap M, Pawlik JR (1998) Spongivory by parrotfish in Florida mangrove and reef habitats. PSZN I: Mar Ecol 19:325-337

English S, Wilkinson C, Baker V (1997) Survey manual for tropical marine resources, 2nd edn. Australian Institute of Marine Science, Townsville

Hay ME, Fenical W (1996) Chemical ecology and marine biodiversity: insights and products from the sea. Oceanography 9:10-20

> Kubanek J, Pawlik JR, Eve TM, Fenical W (2000) Triterpene glycosides defend the Caribbean reef sponge Erylus formosus from predatory fishes. Mar Ecol Prog Ser 207:69-77

> Kubanek J, Whalen KE, Engel S, Kelly SR, Henkel TP, Pawlik JR (2002) Multiple defensive roles for triterpene glycosides from two Caribbean sponges. Oecologia 131: $125-136$ 
Levin PS, Ellis J, Petrik R, Hay ME (2002) Indirect effects of feral horses on estuarine communities. Conserv Biol 16: 1364-1371

Lindel T, Hoffmann H, Hochgürtel M, Pawlik JR (2000) Structure-activity relationship of the inhibition of fish feeding by sponge-derived and synthetic pyrrole-imidazole alkaloids. J Chem Ecol 26:1477-1496

Lindquist N, Bolser R, Laing K (1997) Timing of larval release by two Caribbean demosponges. Mar Ecol Prog Ser 155: 309-313

McMurray SE, Blum JE, Pawlik JR (2008) Redwood of the reef: growth and age of the giant barrel sponge Xestospongia muta in the Florida Keys. Mar Biol 155:159-171

Morrison D (1988) Comparing fish and urchin grazing in shallow and deeper coral reef algal communities. Ecology 69:1367-1382

Oksanen L (2001) Logic of experiments in ecology: is pseudoreplication a pseudoissue? Oikos 94:27-38

O'Neal W, Pawlik JR (2002) A reappraisal of the chemical and physical defenses of Caribbean gorgonian corals against predatory fishes. Mar Ecol Prog Ser 240:117-126

Pavia H, Toth GB, Åberg P (2002) Optimal defense theory: elasticity analysis as a tool to predict intraplant variation in defenses. Ecology 83:891-897

Pawlik JR (1997) Fish predation on Caribbean reef sponges: an emerging perspective of chemical defenses. Proc 8th Int Coral Reef Symp 2:1255-1258

Pawlik JR (1998) Coral reef sponges: Do predatory fishes affect their distributions? Limnol Oceanogr 43:1396-1399

Pawlik JR, Chanas B, Toonen RJ, Fenical W (1995) Defenses of Caribbean sponges against predatory reef fish: I. Chemical deterrency. Mar Ecol Prog Ser 127:183-194

Editorial responsibility: Pei-Yuan Qian,

Kowloon, Hong Kong, SAR
Randall JE, Hartman WD (1968) Sponge feeding fishes of the West-Indies. Mar Biol 1:216-225

Rhoades DF (1979) Evolution of plant chemical defense against herbivores. In: Rosenthal, GA, Janzen, DH (eds) Herbivores: their interaction with secondary plant metabolism. Academic Press, New York, p 3-54

Schmahl GP (1991) Community structure and ecology of sponges associated with four southern Florida coral reefs. In: Rützler, K (ed) New perspectives in sponge biology. Smithsonian Institution Press, Washington, DC, p 376-383

Stamp N (2003) Out of the quagmire of plant defense hypotheses. Q Rev Biol 78:23-55

Stowe KA, Marquis RJ, Hochwender CG, Simms EL (2000) The evolutionary ecology of tolerance to consumer damage. Annu Rev Ecol Syst 31:565-595

Tsurumi M, Reiswig HM (1997) Sexual versus asexual reproduction in an oviparous rope-form sponge, Aplysina cauliformis (Porifera; Verongida). Invertebr Reprod Dev 32:1-9

> Walters KD, Pawlik JR (2005) Is there a trade-off between wound-healing and chemical defenses among Caribbean reef sponges? Integr Comp Biol 45:352-358

Wilkinson CR, Cheshire AC (1988) Growth rate of Jamaican coral reef sponges after hurricane Allen. Biol Bull 175: 175-179

Wilson DM, Puyana M, Fenical W, Pawlik JR (1999) Chemical defense of the Caribbean reef sponge Axinella corrugata against predatory fishes. J Chem Ecol 25:2811-2823

Wulff JL (1994) Sponge feeding by Caribbean angelfishes, trunkfishes, and filefishes. In: VanSoest RWM, VanKempen TMG, Braekman JC (eds) Sponges in time and space. Balkema, Rotterdam, p 265-271

Submitted: June 11, 2008; Accepted: February 7, 2008

Proofs received from author(s): September 9, 2008 